\title{
ATIVIDADE ANTIOXIDANTE, CITOTÓXICA E ANTIMICROBIANA DE Annona vepretorum MART. (ANNONACEAE) ${ }^{1}$
}

\author{
JACKSON ROBERTO GUEDES DA SILVA ALMEIDA², CAMILA DE SOUZA ARAÚJO, \\ CLÁUDIA DO Ó PESSOA ${ }^{4}$, MARCÍLIA PINHEIRO DA COSTA ${ }^{5}$, \\ ALESSANDRA GOMES MARQUES PACHECO ${ }^{6}$
}

RESUMO - Annona vepretorum Mart. é uma espécie endêmica do bioma Caatinga, conhecida no Nordeste do Brasil como "araticum". Neste trabalho, o conteúdo de fenóis totais foi determinado pelo método de Folin-Ciocalteu. O teor de flavonoides totais também foi medido. A atividade antioxidante dos extratos foi analisada pelos métodos do sequestro do radical DPPH e inibição da auto-oxidação do $\beta$-caroteno, e comparada com o ácido ascórbico, BHA e BHT, utilizados como compostos de referência. A análise de citotoxidade foi realizada frente a linhagens de células HCT-116, OVCAR-8 e SF-295. O efeito antibacteriano foi avaliado pelo método de microdiluição. O conteúdo de fenóis totais do extrato etanólico (Av-EtOH) foi de 76,60 \pm $5,57 \mathrm{mg}$ de equivalente de ácido gálico/g. O conteúdo de flavonoides foi de 194,50 $\pm 11,72 \mathrm{mg}$ de equivalente de catequina/g para o extrato hexânico. $\mathrm{O}$ extrato $\mathrm{EtOH}$ exibiu boa atividade antioxidante $\left(\mathrm{IC}_{50}=98,87 \pm\right.$ $11,24 \mathrm{mg} / \mathrm{mL}$ ) no método do DPPH. Os extratos mostraram atividade citotóxica e antibacteriana contra a maior parte das células e microrganismos testados. Pesquisas adicionais serão realizadas para o isolamento e a identificação dos principais constituintes fenólicos dos extratos.

Termos para indexação: araticum, anonácea, atividade biológica.

\section{ANTIOXIDANT, CYTOTOXIC AND ANTIMICROBIAL ACTIVITY OF Annona vepretorum MART. (ANNONACEAE)}

\begin{abstract}
Annona vepretorum Mart. is an endemic species to the Caatinga biome known in Northeast Brazil as "araticum". Phenolic compounds were determined in extracts of leaves. The total phenolic content was determined by the Folin-Ciocalteu method. Total flavonoid content was also measured. Antioxidant activities of the extracts were assayed by DPPH radical scavenging and inhibition of $\beta$-carotene-linoleic acid bleaching and compared with ascorbic acid, BHA and BHT, used as reference compounds. Cytotoxicity analysis in HCT-116, OVCAR-8 and SF-295 cells were carried out. The antibacterial effect was evaluated by the method of microdilution. The total phenolic content of ethanolic extract (Av-EtOH) was $76.60 \pm 5.57 \mathrm{mg}$ of gallic acid equivalent/g. The total flavonoid content was $194.50 \pm 11.72 \mathrm{mg}$ of catechin equivalent $/ \mathrm{g}$ for the hexane extract. The EtOH extract exhibited good antioxidant activity, with an $\mathrm{IC}_{50}$ of $98.87 \pm 11.24 \mu \mathrm{g} / \mathrm{ml}$. The extracts showed cytotoxic and antibacterial activities against most of the line cells and microorganisms tested. Further research will be carried out to achieve the isolation and identification of the main phenolic constituents of the extracts.
\end{abstract}

Index terms: araticum, Annonaceae, biological activity.

\footnotetext{
${ }^{1}$ (Trabalho 069-13) - Recebido em: 14-03-2013. Aceito para publicação em: 12-11- 2013. V Congresso Internacional \& Encontro Brasileiro sobre Annonaceae: do gene à exportação (19 a 23 de Agosto de 2013)-Botucatu-SP.

${ }^{2}$ Ph.D., Núcleo de Estudos e Pesquisas de Plantas Medicinais, Universidade Federal do Vale do São Francisco, 56.304-205, Petrolina-PE, Brasil. E-mail: jackson.guedes@univasf.edu.br

${ }^{3}$ Mestranda em Recursos Naturais do Semiárido, Universidade Federal do Vale do São Francisco, Petrolina-PE, Brasil. E-mail: milasouzaraujo@gmail.com.

${ }^{4}$ Ph.D., Pesquisadora do Laboratório Nacional de Oncologia Experimental, Universidade Federal do Ceará, Fortaleza-CE, Brasil. E-mail: cpessoa@ufc.br

${ }^{5}$ Ph.D., Pesquisadora do Laboratório Nacional de Oncologia Experimental, Universidade Federal do Ceará, Fortaleza-CE, Brasil. E-mail: marciliacosta@hotmail.com

${ }^{6}$ Doutoranda em Biotecnologia. Universidade Estadual de Feira de Santana, Feira de Santana-BA, Brasil. E-mail: alessandragmarques@ hotmail.com
} 


\section{INTRODUÇÃO}

A família Annonaceae apresenta uma combinação de caracteres marcantes e é uma das mais uniformes tanto do ponto de vista anatômico como estrutural, sendo considerada uma das famílias mais primitivas entre as Angiospermas. Essa família é caracterizada pela presença de terpenoides (principalmente diterpenos), alcaloides derivados de isoquinolinas, além de óleos essenciais, cuja composição é predominantemente de monoterpenos e sesquiterpenos (SILVA et al., 2009). É constituída por 120 gêneros e, aproximadamente, 2.000 espécies, distribuídas principalmente nas regiões tropicais do mundo. Dos gêneros que compõem essa família, 34 podem ser encontrados na América do Sul, onde predominam os gêneros Annona L., Duguetia St. Hil., Guatteria Ruiz et Pavon, Rollinia St. Hil. e Xylopia L. (FECHINE et al., 2002). No Brasil, ocorrem 29 gêneros e cerca de 386 espécies, sendo que destes, 1 gênero e 158 espécies são endêmicas (MAAS et al., 2012).

O gênero Annona L. pertence à família Annonaceae e compreende cerca de 114 espécies, sendo 110 neotropicais e 4 africanas (COSTA et al., 2011). No Brasil, ocorrem 81 espécies; destas, 25 são endêmicas, estando distribuídas em regiões como a Amazônia, Caatinga, Cerrado, Mata Atlântica e Pantanal (MAAS et al., 2012). Este gênero é conhecido pelos seus frutos comestíveis e pelo uso de várias espécies na medicina popular. Alguns estudos fitoquímicos relatam o isolamento de alcaloides, acetogeninas, flavonoides, óleos essenciais, diterpenos e lignoides (COSTA et al., 2011) com importantes atividades biológicas, tais como: citotóxica, antitumoral, pesticida, vermicida, antimicrobiana, imunossupressora, antiemética, inibidora do apetite e antimalárica (SANTOS, 2007).

Annona vepretorum Mart. é uma espécie conhecida popularmente na região Nordeste do Brasil como araticum (COSTA et al., 2011), é endêmica do Brasil e com distribuição na Caatinga (MAAS et al., 2012). Em Sergipe, segundo a população local, as raízes dessa planta, quando maceradas, apresentam indicação contra picadas de abelhas, além do emprego como um anti-inflamatório natural (COSTA et al., 2011).

$\mathrm{Na}$ literatura consultada, há poucos relatos de estudos químicos e biológicos com esta espécie. Assim, objetivou-se neste trabalho investigar as atividades antioxidante, citotóxica e antimicrobiana de Annona vepretorum Mart. usando modelos experimentais in vitro.

\section{MATERIAL E MÉTODOS}

Coleta do material botânico-As folhas de Annona vepretorum (Annonaceae) foram coletadas em uma área da Caatinga, no município de Petrolina, Pernambuco. Uma exsicata da espécie (\#3161) está depositada no Herbário Vale do São Francisco (HVASF), na Universidade Federal do Vale do São Francisco (UNIVASF).

Processamento do material vegetal e obtenção dos extratos- Foi realizado no Núcleo de Estudos e Pesquisas de Plantas Medicinais da UNIVASF. As folhas secas e pulverizadas $(430,8 \mathrm{~g})$ foram submetidas à extração com EtOH 95\%, à temperatura ambiente. Foram realizadas três extrações, com intervalos de $72 \mathrm{~h}$. A solução extrativa foi concentrada sob vácuo e, após destilação do solvente, forneceu 164,8 g de extrato etanólico bruto (Av-EtOH). AvEtOH foi suspenso em uma mistura de $\mathrm{MeOH}: \mathrm{H}_{2} \mathrm{O}$ (3:7) e particionado com hexano e clorofórmio em ordem crescente de polaridade para obter os extratos hexânico (Av-Hex) e clorofórmico ( $\left.\mathrm{Av}-\mathrm{CHCl}_{3}\right)$.

Determinação de fenóis totais-O conteúdo de compostos fenólicos totais foi medido para cada extrato, conforme o método de Slinkard \& Singleton (1977), com adaptações (ALMEIDA et al., 2011), usando o reagente de Folin-Ciocalteu e padrão de ácido gálico. $\mathrm{O}$ teor de fenóis totais foi expresso como mg de equivalentes de ácido gálico por grama de amostra (mg EqAG/g), através da curva de calibração com ácido gálico. A faixa da curva de calibração foi $50-1.000 \mathrm{mg} / \mathrm{L}$. Todas as análises foram realizadas em triplicata.

Determinação do teor de flavonoides totais$\mathrm{O}$ teor total de flavonoides totais foi determinado usando um método colorimétrico descrito por Dewanto et al. (2002). Os resultados foram expressos em $\mathrm{mg}$ de equivalentes de catequina por grama de extratos (mg de EqC/g) por meio da curva de calibração com catequina. A curva de calibração foi obtida com concentrações de catequina variando de $50-1.000 \mathrm{mg} / \mathrm{L}$. As análises foram realizadas em triplicata.

Avaliação da atividade antioxidante in vitroPara a análise da atividade antioxidante, foram realizados os ensaios do sequestro do radical livre 2,2-difenil-1-picrilhidrazil (DPPH) e o da cooxidação do $\beta$-caroteno/ácido linoleico. A capacidade de sequestro do radical livre foi medida utilizando metodologia descrita por Mensor et al. (2001). Os ensaios foram realizados em triplicata. Os valores de $\mathrm{IC}_{50}$ foram calculados por regressão linear utilizando o programa GraphPad Prism versão 5.0. O teste da inibição da auto-oxidação do $\beta$-caroteno foi realizado 
seguindo metodologia descrita por Wannes et al. (2010). Este método é baseado na perda da cor amarela do $\beta$-caroteno, devido à sua reação com os radicais formados pela oxidação do ácido linoleico por uma emulsão. O ácido ascórbico, BHT e BHA foram usados como controle positivo. Os resultados foram expressos como percentagem de atividade antioxidante (\% AA). Os testes foram realizados em triplicata.

Avaliação da atividade citotóxica- Para avaliar a atividade citotóxica, foi realizada a análise de citotoxidade pelo método do MTT, sendo esse um método rápido, sensível e barato. Foi descrito primeiramente por Mosmann (1983), tendo a capacidade de analisar a viabilidade e o estado metabólico da célula. É uma análise colorimétrica baseada na conversão do sal 3-(4,5-dimetil-2-tiazol)2,5-difenil-2-H-brometo de tetrazolium (MTT) em azul de formazan, a partir de enzimas mitocondriais presentes somente nas células metabolicamente ativas. $\mathrm{O}$ estudo de atividade citotóxica pelo método do MTT permite definir facilmente a citotoxidade, mas não o mecanismo de ação (BERRIDGE et al., 1996). Para a análise da citotoxidade, as linhagens tumorais utilizadas foram HCT-116 (colorretal humano), OVCAR-8 (ovário humano) e SF-295 (glioblastoma humano), cedidas pelo Instituto Nacional do Câncer (EUA), tendo sido cultivadas em meio RPMI 1640, suplementados com 10\% de soro fetal bovino e $1 \%$ de antibióticos, mantidas em estufa a $37{ }^{\circ} \mathrm{C}$ e atmosfera contendo $5 \%$ de $\mathrm{CO}_{2}$. As amostras foram diluídas em DMSO PA estéril. Os extratos foram testados na concentração de 50 $\mu \mathrm{g} / \mathrm{mL}$. As linhagens celulares utilizadas foram plaqueadas nas concentrações de $0,1 \times 10^{6}$ células $/ \mathrm{mL}$ (HCT-116), 0,1 x $10^{6}$ células/mL (OVCAR-8) e 0,7 x $10^{5}$ células $/ \mathrm{mL}$ (SF-295). As placas foram incubadas por 72 horas, em estufa a $5 \%$ de $\mathrm{CO}_{2}$ a $37{ }^{\circ} \mathrm{C}$. Ao término deste, as mesmas foram centrifugadas, e o sobrenadante foi removido. Em seguida, foram adicionados $150 \mu \mathrm{L}$ da solução de MTT (sal de tetrazolium), e as placas foram incubadas por $3 \mathrm{~h}$. A absorbância foi lida após a dissolução do precipitado com $150 \mu \mathrm{L}$ de DMSO puro em espectrofotômetro de placa, a $595 \mathrm{~nm}$. Os experimentos foram analisados segundo a média \pm desvio-padrão da média (DPM) da porcentagem de inibição do crescimento celular, usando o programa GraphPad Prism. Cada amostra foi testada em triplicata, em dois experimentos independentes. Uma escala de intensidade foi utilizada para avaliar o potencial citotóxico das amostras testadas: amostras sem atividade (SA), com pouca atividade (PA, inibição de crescimento celular variando de 1 a $50 \%$ ), com atividade moderada
(MO, inibição de crescimento celular variando de 50 a 75\%) e com muita atividade (MA, inibição de crescimento variando de 75 a $100 \%$ ).

Avaliação da atividade antimicrobiana- Para a avaliação da atividade antimicrobiana, as cepas bacterianas de referência utilizadas foram obtidas do Instituto Nacional de Controle de Qualidade em Saúde (INCQS/FIOCRUZ - Brasil). Os microrganismos utilizados foram: Bacillus cereus (ATCC 11778), Enterococcus faecalis (ATCC 19433), Escherichia coli (ATCC 25922), Klebsiella pneumoniae (ATCC 13883), Salmonella enterica (ATCC 10708), Serratia marcescens (ATCC 13880), Shigella flexneri (ATCC 12022) e Staphylococcus aureus (ATCC 25923). Foi realizada a determinação da concentração inibitória mínima (CIM) e concentração bactericida mínima (CBM), e o efeito antibacteriano foi avaliado pelo método de microdiluição (SANTOS et al., 2012), como recomendado pelo The National Committee for Clinical Laboratory Standards (CLSI, 2003). Inicialmente, uma solução-mãe de $25 \mathrm{mg} / \mathrm{mL}$ dos extratos foi preparada, utilizando uma solução aquosa de DMSO a 20\% (v/v). Foram transferidos $200 \mu \mathrm{L}$ desta diluição para a microplaca contendo $200 \mu \mathrm{L}$ de caldo Muller-Hinton. Posteriormente, diluições seriadas foram realizadas, resultando em concentrações de $25 ; 12,5 ; 6,25 ; 3,12 ; 1,56 ; 0,78$; 0,39 e $0,195 \mathrm{mg} / \mathrm{mL}$. O inóculo contendo $5 \times 10^{5}$ $\mathrm{UFC} / \mathrm{mL}$ (0,5 na escala de McFarland) foi adicionado a cada poço. Foram reservados poços nas microplacas para controle de esterilidade do caldo, do crescimento bacteriano e da ação do antimicrobiano de referência (Gentamicina). Para a gentamicina, foi usada uma concentração inicial de $1,6 \mathrm{mg} / \mathrm{mL}$, a qual foi diluída para concentrações de 0,$8 ; 0,4 ; 0,2 ; 0,1 ; 0,05 ; 0,025$ e $0,0125 \mathrm{mg} / \mathrm{mL}$. As microplacas foram incubadas sob condições de aerobiose durante $18-24$ horas, a $37^{\circ} \mathrm{C}$, quando $10 \mu \mathrm{L}$ de cloreto de 2,3,5-trifenil-tetrazólio (CTT) a $2 \%$ foram adicionados a cada poço para a detecção da mudança de cor do CTT (incolor) para vermelho, que reflete o metabolismo bacteriano ativo. A CIM foi definida com a concentração mais baixa do extrato que, visivelmente, inibiu o crescimento bacteriano. Para determinar a CBM, alíquotas de 10 $\mu \mathrm{L}$ foram retiradas de cada um dos poços contendo os extratos e transferidas para placas de Petri contendo ágar Muller-Hinton. As placas foram incubadas durante 24 horas, a $37^{\circ} \mathrm{C}$. O surgimento de colônia de bactéria para uma dada concentração indica que essa não foi capaz de matar 99,9\% ou mais de inóculo bacteriano utilizado. Os ensaios foram realizados em triplicata. A densidade do extrato foi empregada para converter $\mu \mathrm{L} / \mathrm{mL}$ em $\mathrm{mg} / \mathrm{mL}$, sendo este último utilizado para expressar os valores de CIM e CBM. 


\section{RESULTADOS E DISCUSSÃO}

Os radicais de oxigênio (radicais hidroxila e peroxila) e o ânion superóxido têm um papel importante nas reações bioquímicas/fisiológicas do corpo humano. No entanto, se houver produção excessiva de radicais de oxigênio durante os processos patofisiológicos ou devido a fatores ambientais adversos e não existirem antioxidantes disponíveis in vivo, podem ocorrer doenças e danos profundos em tecidos (DUARTE-ALMEIDA, 2006). O interesse pela descoberta de antioxidantes novos e seguros de fontes naturais tem aumentado, principalmente para prevenir o dano oxidativo às células vivas, enquanto o uso de antioxidantes sintéticos tem diminuído devido à suspeita de atividade como promotores de carcinogênese (LIMA et al., 2010).

Com o intuito de avaliar o efeito dos extratos de Annona vepretorum como antioxidantes, foram realizados testes de atividade antioxidante in vitro, usando o método do sequestro do radical livre $\mathrm{DPPH}$, em que o extrato etanólico (Av-EtOH) obteve melhor efeito antioxidante $\left(\mathrm{IC}_{50}\right.$ igual a $98,87 \pm$ $11,24 \mu \mathrm{g} / \mathrm{mL}$ ), além do método da cooxidação do $\beta$-caroteno/ácido linoleico, sendo que, neste método, o extrato com melhor atividade antioxidante foi $o$ hexânico (Av-Hex), com porcentagem de atividade antioxidante igual a $34,28 \pm 6,62 \%$ (baixa atividade), como observado na Tabela 1.

Dentre os resultados obtidos para a citotoxidade, pode-se observar que todos os extratos apresentaram atividade variando de moderada (MO, inibição de crescimento celular de 50 a 75\%) a muita atividade (MA, inibição de crescimento de 75 a 100\%). Apesar de nenhum dos extratos apresentar muita atividade contra as três linhagens tumorais, o extrato etanólico (Av-EtOH) promoveu inibição de crescimento celular de $90,32 \%$ e $100 \%$ frente às linhagens OVCAR-8 (ovário humano) e HCT-116 (colorretal humano), respectivamente. Os extratos hexânico (Av-Hex) e $\mathrm{CHCl}_{3}\left(\mathrm{Av}-\mathrm{CHCl}_{3}\right)$ obtiveram valores moderados quando testados frente às linhagens OVCAR-8 e SF-295 (glioblastoma humano), e ambos foram muito ativos contra a linhagem HCT-116, com resultados de 94,95 e 100\%, respectivamente (Tabela 2).

Em relação à atividade antimicrobiana, não existe um consenso sobre o nível de inibição aceitável para produtos naturais quando comparados com antibióticos padrões, tanto que alguns autores consideram somente resultados similares aos de antibióticos, enquanto outros consideram com bom potencial mesmo aqueles com níveis de inibições superiores (DUARTE, 2006). Aligianis et al. (2001) propuseram uma classificação para materiais vegetais com base nos resultados de CIM, considerando como: forte inibição - CIM até $500 \mu \mathrm{g} / \mathrm{mL}$; inibição moderada - CIM entre 600 e $1.500 \mu \mathrm{g} / \mathrm{mL}$ e como fraca inibição - CIM acima de $1.600 \mu \mathrm{g} / \mathrm{mL}$.

Dentre os resultados obtidos para a determinação da concentração inibitória mínima (CIM),pode-se considerar como forte a ação dos extratos etanólico (Av-EtOH) e hexânico (Av-Hex) frente à bactéria Escherichia coli, com valores de $0,39 \mathrm{mg} / \mathrm{mL}$. O extrato hexânico (Av-Hex) ainda inibiu fortemente o crescimento do microrganismo Salmonela choleraesuis com resultado de $0,39 \mathrm{mg} /$ $\mathrm{mL}$, como também apresentou moderada atividade contra Serratia marcescens e Staphylococcus aureus. $\mathrm{O}$ extrato clorofórmico ( $\left.\mathrm{Av}-\mathrm{CHCl}_{3}\right)$ apresentou moderada atividade contra Escherichia coli. Todos os extratos apresentaram fraca atividade frente aos demais microrganismos (Tabela 3). 
TABELA 1- Fenóis totais (FT), flavonoides totais (FT) e atividade antioxidante in vitro do extrato etanólico $(\mathrm{EtOH})$ e demais frações (Hexano e $\mathrm{CHCl}_{3}$ ) obtidos das folhas de Annona vepretorum (Annonaceae).

\begin{tabular}{|c|c|c|c|c|}
\hline Amostras & $\begin{array}{l}\text { Fenóis totais } \\
\text { (mg EqAG/g) }\end{array}$ & $\begin{array}{l}\text { Flavonoides totais } \\
(\mathrm{mg} \mathrm{EqC/g})\end{array}$ & $\begin{array}{c}\text { DPPH } \\
\left(\mathrm{IC}_{50}, \mu \mathrm{g} / \mathrm{ml}\right)\end{array}$ & $\begin{array}{c}\beta \text {-caroteno } \\
(\% \text { AA })\end{array}$ \\
\hline $\mathrm{Av}-\mathrm{EtOH}$ & $76,60 \pm 5,57$ & $63,87 \pm 0,58$ & $98,87 \pm 11,24$ & $21,26 \pm 0,54$ \\
\hline Av-Hex & $31,27 \pm 1,53$ & $194,5 \pm 11,72$ & $491,90 \pm 27,19$ & $34,28 \pm 6,62$ \\
\hline $\mathrm{Av}-\mathrm{CHCl}_{3}$ & $38,93 \pm 1,53$ & $120,40 \pm 0,58$ & $134,90 \pm 11,81$ & $29,61 \pm 5,78$ \\
\hline Ácido ascórbico & --- & -- & $3,13 \pm 0,15$ & $7,63 \pm 1,48$ \\
\hline BHA & --- & --- & $3,51 \pm 0,12$ & $83,11 \pm 1,94$ \\
\hline BHT & --- & --- & $8,09 \pm 1,52$ & $87,90 \pm 9,35$ \\
\hline
\end{tabular}

Os valores de $\mathrm{CI}_{50}$ foram obtidos por interpolação a partir da análise de regressão linear com $95 \%$ de intervalo de confiança. $\mathrm{CI}_{50}$ é definido como a concentração suficiente para se obter $50 \%$ de uma estimativa de efeito máximo em $100 \%$. Os valores são apresentados como média \pm desvio-padrão $(\mathrm{n}=3)$.

TABELA 2- Percentual de inibição de crescimento apresentado pelos extratos contra três linhagens de células tumorais.

\begin{tabular}{lccc}
\hline \multirow{2}{*}{ Amostras } & OVCAR-8 & SF-295 & HCT-116 \\
\cline { 2 - 4 } & Média & Média & Média \\
\hline $\mathrm{Av}-\mathrm{EtOH}$ & $(\mathrm{MA}) 90,32 \%$ & $(\mathrm{MO}) 59,99 \%$ & (MA) $100 \%$ \\
$\mathrm{Av}-\mathrm{Hex}$ & $(\mathrm{MO}) 53,74 \%$ & $(\mathrm{MO}) 66,95 \%$ & (MA) $94,95 \%$ \\
$\mathrm{Av}-\mathrm{CHCl}_{3}$ & (MO) $53,54 \%$ & (MO) $71,19 \%$ & (MA) $100 \%$ \\
\hline
\end{tabular}

OVCAR-8 (ovário humano), SF-295 (glioblastoma humano), HCT-116 (colorretal humano). Amostras sem atividade (SA), com pouca atividade (PA, inibição de crescimento celular variando de 1 a 50\%), com atividade moderada (MO, inibição de crescimento celular variando de 50 a $75 \%$ ) e com muita atividade (MA, inibição de crescimento variando de 75 a $100 \%$ ).

TABELA 3- Atividade antimicrobiana do extrato etanólico (Av-EtOH), hexânico (Av-Hex) e clorofórmico $\left(\mathrm{Av}-\mathrm{CHCl}_{3}\right)$ de Annona vepretorum.

\begin{tabular}{|c|c|c|c|c|c|c|}
\hline \multirow[b]{2}{*}{ Microrganismo } & \multicolumn{2}{|c|}{ Av-EtOH } & \multicolumn{2}{|c|}{ Av-Hex } & \multicolumn{2}{|c|}{$\mathrm{Av}-\mathrm{CHCl}_{2}$} \\
\hline & $\begin{array}{c}\text { CIM } \\
(\mathrm{mg} / \mathrm{mL})\end{array}$ & $\begin{array}{c}\mathrm{CBM} \\
(\mathrm{mg} / \mathrm{mL})\end{array}$ & $\begin{array}{c}\text { CIM } \\
(\mathrm{mg} / \mathrm{mL})\end{array}$ & $\begin{array}{c}\mathrm{CMB} \\
(\mathrm{mg} / \mathrm{mL})\end{array}$ & $\begin{array}{c}\mathrm{CIM} \\
(\mathrm{mg} / \mathrm{mL})\end{array}$ & $\begin{array}{c}\mathrm{CMB} \\
(\mathrm{mg} / \mathrm{mL})\end{array}$ \\
\hline Bacillus cereus & 12,5 & 12,5 & 6,25 & 6,25 & 12,5 & 12,5 \\
\hline Enterococcus faecalis & 3,12 & 6,25 & 3,12 & 3,12 & 12,5 & 12,5 \\
\hline Escherichia coli & 0,39 & 1,56 & 0,39 & 3,12 & 0,78 & 6,25 \\
\hline Klebsiella pneumoniae & 3,12 & 6,25 & 3,12 & 12,5 & 6,25 & 12,5 \\
\hline Salmonela choleraesuis & 3,12 & 12,5 & 0,39 & 12,5 & 6,25 & 12,5 \\
\hline Serratia marcescens & 3,12 & 12,5 & 0,78 & 12,5 & 3,12 & 6,25 \\
\hline Shigella flexneri & 1,56 & 3,12 & 1,56 & 6,25 & 3,12 & 6,25 \\
\hline Staphylococcus aureus & 3,12 & 12,5 & 0,78 & 12,5 & 1,56 & - \\
\hline
\end{tabular}

CIM: concentração inibitória mínima. CBM: concentração bactericida mínima. 


\section{CONCLUSÃO}

Os extratos de Annona vepretorum apresentaram atividade antioxidante, citotóxica e antimicrobiana. As atividades apresentadas podem estar relacionadas à presença de constituintes químicos nos extratos, principalmente flavonoides, esteroides e terpenoides. Estudos estão sendo realizados para a determinação da estrutura dos constituintes químicos encontrados nesta espécie.

\section{AGRADECIMENTOS}

Os autores agradecem à FACEPE e ao CNPq, pelo auxílio financeiro para a realização da pesquisa, e à CAPES, pela bolsa de mestrado concedida a Camila de Souza Araújo.

\section{REFERÊNCIAS}

ALIGIANIS, N.; KALPOUTZAKIS, E.; MITAKU, S.; CHINOU, I. B. Composition and antimicrobial activity of the essential oil of two Origanum species, Journal of Agricultural and Food Chemistry, Washington, v. 49, n. 9, p. 4.168-4.170, 2001.

ALMEIDA, J. R. G. S.; OLIVEIRA, M. R.; GUIMARÃES, A. L.; OLIVEIRA, A. P.; RIBEIRO, L. A. A.; LÚCIO, A. S. S. C.; QUINTANS-JÚNIOR, L. J. Phenolic quantification and antioxidant activity of Anaxagorea dolichocarpa and Duguetia chrysocarpa (Annonaceae). International Journal of Pharma and Bio Sciences, South Jordan, v. 2, n. 4, p. 367-374, 2011.

BERRIDGE, M. V.; TAN, A. S.; McCOY, K. D.; WANG, R. The Biochemical and Cellular Basis of Cell Proliferation Assays that Use Tetrazolium Salts. Biochemica, Berlin, v. 4, p. 14-19, 1996.

CLSI - Clinical Laboratory Standards Institute. Metodologia dos testes de sensibilidade a agentes antimicrobianos por diluição para bactérias de crescimento aeróbico: norma aprovada. 6.ed. São Paulo, 2003. v.23, M7-A6.

COSTA, E. V.; DUTRA, L. M.; JESUS, H. C. R.; NOGUEIRA, P. C. L.; MORAES, V. R. S.; SAlVADOR, M. J.; PRATA, A. P. N. Composição química e atividade antimicrobiana do óleo essencial das folhas de Annona vepretorum Mart. (Annonaceae). In: REUNIÃO ANUAL DA SOCIEDADE BRASILEIRA DE QUÍMICA, 34., 2011, Florianópolis. Anais..
DEWANTO, V.; WU, X.; ADOM, K.; LIU, R. H. J. Processed sweet corn has higher antioxidant activity. Journal of Agricultural and Food Chemistry, Washington, v. 50, n. 10, p. 3.010-3.014, 2002.

DUARTE, M. C. T. Atividade antimicrobiana de plantas medicinais e aromáticas utilizadas no Brasil. Revista Multiciência, Campinas, n. 7, 2006.

DUARTE-ALMEIDA, J. M.; SANTOS, R. J.; GENOVESE, M. I.; LAJOLO, F. M. Avaliação da atividade antioxidante utilizando sistema $\beta$-caroteno/ ácido linoleico e método de sequestro de radicais DPPH. Ciência e Tecnologia de Alimentos, Campinas, v. 26, n. 2, p. 446-452, 2006.

FECHINE, I. M.; LIMA, M. A.; NAVARRO, V. R.; CUNHA, E. V. L.; SILVA, M. S.; BARBOSAFILHO, J. M.; MAIA, J. G. S. Alcaloides de Duguetia trunciflora Maas (Annonaceae). Revista Brasileira de Farmacognosia, Curitiba, v. 12, p. 17-19, 2002. Suplemento.

LIMA, A. R.; PEREIRA, R. G. F. A.; ABRAHÃO, S. A.; DUARTE, S. M. S.; PAULA, F. B. A. Compostos bioativos do café: atividade antioxidante in vitro do café verde e torrado antes e após a descafeinação. Química Nova, São Paulo, v. 33, n. 1, p. 20-24, 2010.

MA A S, P.; R A IN ER, H .; L O B Ã O, A. Annonaceae. In: LISTA de espécies da flora do Brasil. Jardim Botânico do Rio de Janeiro. Disponível em: <http://floradobrasil.jbrj.gov. br/2012/FB110219>. Acesso em: 25 dez. 2012.

MENSOR, L. L.; MENEZES, F. S.; LEITÃO, G. G.; REIS, A. S.; SANTOS, T. C.; COUBE, C. S.; LEITÃO, S. G. Screening of Brazilian plant extracts for antioxidant activity by the use of DPPH free radical method. Phytotherapy Research, London, v. 15 , p. 127-130, 2001.

MOSMANN, T. Rapid colorimetric assay for cellular growth and survival: application to proliferation and cytotoxicity assays. Journal of Immunological Methods, Amsterdam, v. 65, p. 55-63, 1983.

SANTOS, L. A. R.; PIMENTA, L. P. S.; BOAVENTURA, M. A. D. Acetogeninas de anonáceas bioativas isoladas das sementes de Annona cornifolia A. St. Hil. Revista Brasileira de Plantas Medicinais, Botucatu, v. 9, n. 3, p. 48-51, 2007. 
SANTOS, T. G.; REBELO, R. A.; DALMARCO, E. M.; GUEDES, A.; GASPER, A. L.; CRUZ, A. B.; SCHIMIT, A. P.; CRUZ, R. C. B.; STEINDEL, M.; NUNES, R. K. Chemical composition and antimicrobial activity of leaf essential oil from Piper malacophyllum (C. Presl.) C. DC. Química Nova, São Paulo, v. 35, p. 477-481, 2012.

SILVA, M. S.; TAVARES, J. F.; QUEIROGA, K. F.; AGRA, M. F.; BARBOSA-FILHO, J. M.; ALMEIDA, J. R. G. S.; SILVA, S. A. S. Alcaloides e outros constituintes de Xylopia langsdorffiana (Annonaceae). Quimíca Nova, São Paulo, v. 32, n. 6, p. 1.566-1.570, 2009
SLINKARD, K.; SINGLETON, V. L. Total phenol analyses automation and comparison with manual methods. American Journal of Enology and Viticulture, Washington, v. 28, p. 49-55, 1977.

WANNES, W. A.; MHAMDI, B.; SRITI, J.; JEMIA, M. B.; OUCHIKH, O.; HAMDAOUI, G.; KCHOUK, M. E.; MARZOUK, B. Antioxidant activities of the essential oil and methanol extracts from myrtle (Myrtus communis var. italica L.) leaf, stem and flower. Food and Chemical Toxicology, Amsterdam, v. 48, p. 1.362-1.370, 2010. 